\title{
Zainketa intentsiboko unitateko pazienteen familiek dituzten beharren berrikusketa
}

(Needs that the intensive care unit patient's families have: a review)

Ekhiñe Unzalu Lerma

Gasteizko Erizaintzako Eskola

ekiunza@gmail.com

DOI: $10.1387 /$ ekaia.14764

Jasoa: 2016-05-10

Onartua: 2016-10-06

Laburpena: Zainketa intentsiboetan ingresatzea bai ospitaleratutakoek bai familiek egoera estresagarri moduan hautematen dute. Egoera horrek shock egoera, antsietatea eta sinesgaiztasuna eragin ditzake. Beraz, artikuluaren helburua izango da ospitaleratzeak irauten duen bitartean familiaren eta pazientearen beharrak ezagutzea.

Hitz gakoak: Familia, Zainketa intentsiboak, Zainketa intentsiboko unitatea, Beharrak.

\begin{abstract}
Admission to the Intensive Care Units (ICU) is perceived by both patients and their family as a stressful experience. This situation can cause shock, scepticism and anxiety in the patient's setting. Therefore, the objective of the article is to know what the needs of families and patients are during de admission.
\end{abstract}

Keywords: Family, Intensive cares, Critical care units, Needs.

\section{SARRERA}

Ospitaleratzea norbanakoarentzat zein inguruko familia-kideentzat eta gertuko senideentzat gertaera estresagarria suertatzen da. 2005. urtean, Espainia mailan, EESCRk (Estadística de establecimientos sanitarios con régimen interno) ospitale akutuetan medikuntza intentsiboko unitateei 4.975 ohe zegozkiela identifikatu zuen, ospitale akutuetan funtzionamenduan dauden oheen $\% 4,3$. Ehuneko horretatik, zainketa intentsiboko unitatean 3.809 ohe zeuden (\% 77), eta gainontzekoak ondorengo unitateetan 
zeuden, ehuneko hauetan banaturik: zainketa koronarioen unitatean $\% 10$, jaioberrien zainketa intentsiboetan \% 11 eta erreduren unitatean \% 2. Zainketa intentsiboetako 3809 ohe horietan 210.984 paziente artatu ziren eta batez besteko egonaldia 4,6 egunekoa izan zen. Unitateen heriotza-tasa $\%$ 10,6koa zela identifikatu zuten [1].

Estrestzat joko da prozesu bat, abian jartzen dena pertsona bat ez denean gai, berezko errekurtsoekin, egoera edo gertaera bati aurre egiteko $[2,3]$. Era berean, aurre egite prozesua definituko da gizabanako batek kanpo- (ingurukoak) zein barne- (egoera emozionala) eskaerei erantzuteko egin behar duen esfortzu kognitibo moduan zein jokaerazko estrategia moduan $[3,4]$.

Gertaera are larriagoa izaten da baldin eta ospitalizazioa zainketa intentsiboko unitatean (ZIU) izaten bada. Izan ere, unitate honetan sartzeak gaixoaren egoera larriagoa dela ulertarazten die bai pazienteari, bai familiari, eta horrek barne hartzen ditu eragin ditzakeen beldur guztiak [5]. Zainketa intentsiboko unitatean, ospitaleko eremu zehatz batean, osasun-langile talde espezializatu batek diziplina anitzeko zainketak eskaintzen dizkie bertako pazienteei. Unitate hauek egitura aldetik, funtzionalitate aldetik zein lan-dinamika aldetik, besteekin alderatuz, arau bereziak dituzte. Gainera, garrantzitsua da azpimarratzea unitate honek ez duela edozein paziente onartzen, bertan ematen diren zainketak espezifikoak izaten direlako, esaterako, arnasketarako edota beste edozein organoren edo sistemaren sostengurako euskarri baten beharra duten pazienteak [1]. Gehienetan, prozesu akutu eta itzulgarriak pairatzen dituzten pazienteak ingresatzen dira.

Orokorrean, Espainiako Zainketa intentsiboko unitateek arau bereziak jarraitzen dituzte, eta horietako bat da bisitek ordutegi mugatua izatea. Bertako espazioak itxiak izaten dira eta langileek erregulatzen dituzte; ondorioz, barruan daudenak (paziente eta osasun-langileek) kanpoan daudenekin izaten duten kontaktua (fisikoa, emozionala eta komunikaziozkoa) urria izaten da, eta kanpokoek erraztasun gutxi izaten dute unitatera sartzeko. Beraz, horien guztien arteko erlazioa bisiten ordutegira mugatzen da [6]. Egoera horrek ondorioak eragiten dizkio pazienteari, estresari loturiko berezko sintomez gain, bestelako zailtasunak sumatuko dituelako. Gaixoa, heriotzaren beldurraz aparte, sufrimenduaren eta mina sentitzearen beldur izango da. Beldur eta urduritasun horiek areagotuko dira pazienteak bizi duen isolamendu eta bakardade egoera honekin; izan ere, zer gertatuko zaion ezjakintasun horretan, bere sentimendu eta beldur horiek guztiak komunikatzeko zailtasuna izango du. Horretaz gain, egoera estresagarri honetan, gaixoak duen autonomia- zein intimitate-falta kontuan hartu behar da [7].

Bestalde, familiek oso egoera zailari aurre egin behar diotela kontuan izan behar dugu. Egoera hori, sarritan, berria eta estresagarria izan ohi da, zeinetan nagusitzen diren ezjakintasun, nahaste, ardura, haserre, beldur 
(heriotzari eta gaixoaren sufrimenduari lehenengo, eta, beldur hori pasatzen denean, gaixoari gera dakizkion ondorio eta galerei), erru eta babesgabetasun sentimenduak. Horrek guztiak egunerokotasunean oreka galtzea eragiten du [8]. Orduan, familia unitatean haustura gerta daiteke, eta horren ondorioz, familia-kideek egoera are zailago bati aurre egin behar izango diote, familia-rolak aldatuko baitira eta heriotzaren beldurra sentituko baitute. Egoera horrek familia-kideengan hainbat nahaste eragin ditzake maila psikologikoan zein sozialean. Horregatik, batzuetan, tratamendu bereziak beharrezkoak izaten dira familia-kideentzat ere [9]; sintoma ohikoenak antsietatea eta depresioa izaten dira, kasuen $\%$ 69,1 eta \% 35,4, hurrenez hurren [10].

\section{HELBURUAK}

Zainketa intentsiboetan ingresatuta dagoen paziente baten senideek ingresoak irauten duen bitartean paira ditzaketen estres egoera eta azalarazten dituzten beharrak identifikatzea eta deskribatzea.

\section{METODOLOGIA}

Lan honetarako proposaturiko helburuak betetzeko ondorengo datubaseak aztertu ziren: Embase, Cinhal, Medline, Psycinfo, Up to Date eta Cochrane Plus.

Bilaketa bibliografikoa egiteko orduan estrategia ezberdinak erabili ziren. Alde batetik, bilaketa egin zen datu-base bakoitzean hitz gakoak erabiliz. Beraz, zainketa intentsiboetako unitateari eta pazienteei dagokienez «intensive care unit», «intensive care» eta «critically ill» hitz gakoak erabili ziren. Unitate honetan ingresatuta dauden pazienteen senideak bizitzen dituzten esperientzien eta beharren inguruan aritzen diren artikuluak bilatzeko, «experience», «personal experience», «life change events», «personal experience», «psychological assessment» eta «life experience» hitz gakoak erabili ziren. Familiari erreferentzia egiteko, ordea, «family», «family member», «relative» eta «visitors to patients» hitz gakoak erabili ziren. Hitz guztien balizko konbinazio guztiak ziurtatzeko, ondorengo operadoreak erabili ziren: $<\mathrm{AND}>$ eta $<\mathrm{OR}>$. Bestetik, egin zen beste bilaketan aurretik aipatu diren datu-base berak erabili ziren eta pauso berdinak jarraitu ziren, baina, kasu honetan, hitz gakoak erabili beharrean hizkuntza arrunta erabili zen. (I. eranskina)

Aipatutako datu-baseetan bilaketa egiteaz aparte, literatura zientifikoaren azterketa kritikorako aipagarriak izan zitezkeen artikuluak identifikatzeko Elsevier argitaletxeak duen interneteko plataforman (DOYMA) 
zenbait bilaketa egin ziren «Medicina Intensiva», «Enfermería Clínica» eta «Enfermería Intensiva» aldizkarietan ondorengo hitz gakoa erabiliz: «UCI», «familia» eta «experiencia».

Osakidetzak eta Euskal Herriko Unibertsitateak online eskuragarri dituzten aldizkarietan ere eskuko bilaketa egin zen, hain zuzen ere, «Intensive and Critical Care Nursing», «Enfermería Intensiva» eta «Enfermería Clínica» aldizkarietan. (II. eranskina)

Ikerketa kualitatibo ia guztiak barne hartu ziren. Hain zuzen ere, lortutako emaitzen datuak aztertzen eta garatzen zituzten ikerketak. Horrek datu-baseetatik edota aldizkari zientifikoetatik ikerlanak lortzea eragin zuen. Aukeratutako artikulu guztien gai nagusiak bi izan ziren: alde batetik, zainketa intentsiboetan ingresatuta zegoen paziente baten senideen beharrei buruz aritzen zirenak eta, bestetik, familiek ingresoak iraun bitartean bizi dezaketen bizipenaz jarduten zirenak.

Zainketa intentsiboetako unitatean ingresatuta dagoen pazientearen familia ikerketaren parte hartzailetzat hartzen zituzten argitalpenak barneratu ziren. Gaixoaz arduratzen diren eta erlazio zuzena eta egunerokoa duten pertsona horiek pazientearen familiatzat hartu ziren, beraien arteko erlazioa edo ahaidetasun maila kontuan hartu gabe. ZIUan lan egiten duten erizainak barne hartzen zituzten ikerlanak ere aintzat hartu ziren.

2000. urtetik gaur egun arte argitaratutako lanak aztertu ziren. Ikerlan zaharragoak ez ziren aintzat hartu informazioa ahalik eta eguneratuena egoteko eta lortutako emaitzen fidagarritasun maila ahalik eta altuena izateko.

Bilaketa euskaraz, gaztelaniaz eta ingelesez argitaratutako lanei mugatu zen.

Jaioberrien zainketa intentsiboko unitateez eta pediatriakoez aritzen ziren artikuluak, ZIUan ingresatuta dagoen pazientearen senideen beharrak eta bizipenak gai nagusitzat ez zituzten artikuluak, erizainak ez diren osasun-profesionalen ikuspuntuak barneratzen zituzten artikuluak eta literatura grisa (buletinak, berriak, aldizkarietako idazkiak, eta abar) ez ziren aintzat hartu.

Datu-base eta aldizkari zientifiko bakoitzean egindako bilaketa bibliografikoaren emaitzetan oinarrituz, artikuluen aukeraketa egin zen. Lehendabizi, izenburuak irakurriz, hautaketa azkarra egin zen. Ondoren, errepikatutako artikuluak baztertu ziren. Jarraian, lehenengo aukeraketa horretako artikuluen laburpenak irakurri ziren eta bigarren aukeraketa bat egin zen. Irakurritako artikulu horietatik, interesgarrienen kasuan bakarrik, testu osoa bilatzea izan zen ondorengo urratsa.

Dena den, bilaketa horretan zenbait oztopo suertatu ziren; izan ere, interesgarriak ziruditen artikulu horien guztien testu osoa ezin izan zen lortu. 
Hortaz, eskuratu ahal zirenekin bakarrik jarraitu zen analisia egiten. Horretarako, ondorengo pausoak eman ziren:

1. Aukeratutako artikuluen irakurketa sakona, bertan agertzen ziren eta lan honekin zerikusia zuten helburuekin zein informazio garrantzitsuenarekin lotutako ideiak identifikatzea, horretarako, datu esanguratsuak azpimarratuz. Aldi berean, artikuluek barneratze-irizpideak betetzen zituztela egiaztatu zen.

2. Artikuluetan azpimarratutako datu garrantzitsuen analisia eta hausnarketa egin zen.

3. Behin hausnarketa eginda, lortutako informazioa sailkatu zen eta lan honen helburuei erantzun garrantzitsua eskaintzen zuten artikuluak aukeratu ziren.

4. Beraz, pauso horiek jarraituta, zortzi izan ziren lan honen helburuak lortzeko aukeratutako artikuluak. (1. irudia)

Ez zen artikuluen kalitate metodologikoaren ebaluaketarik egin; izan ere, kalitate goreneko artikuluak izan ez arren, lan honen helburuei erantzuteko baliagarriak ziren.

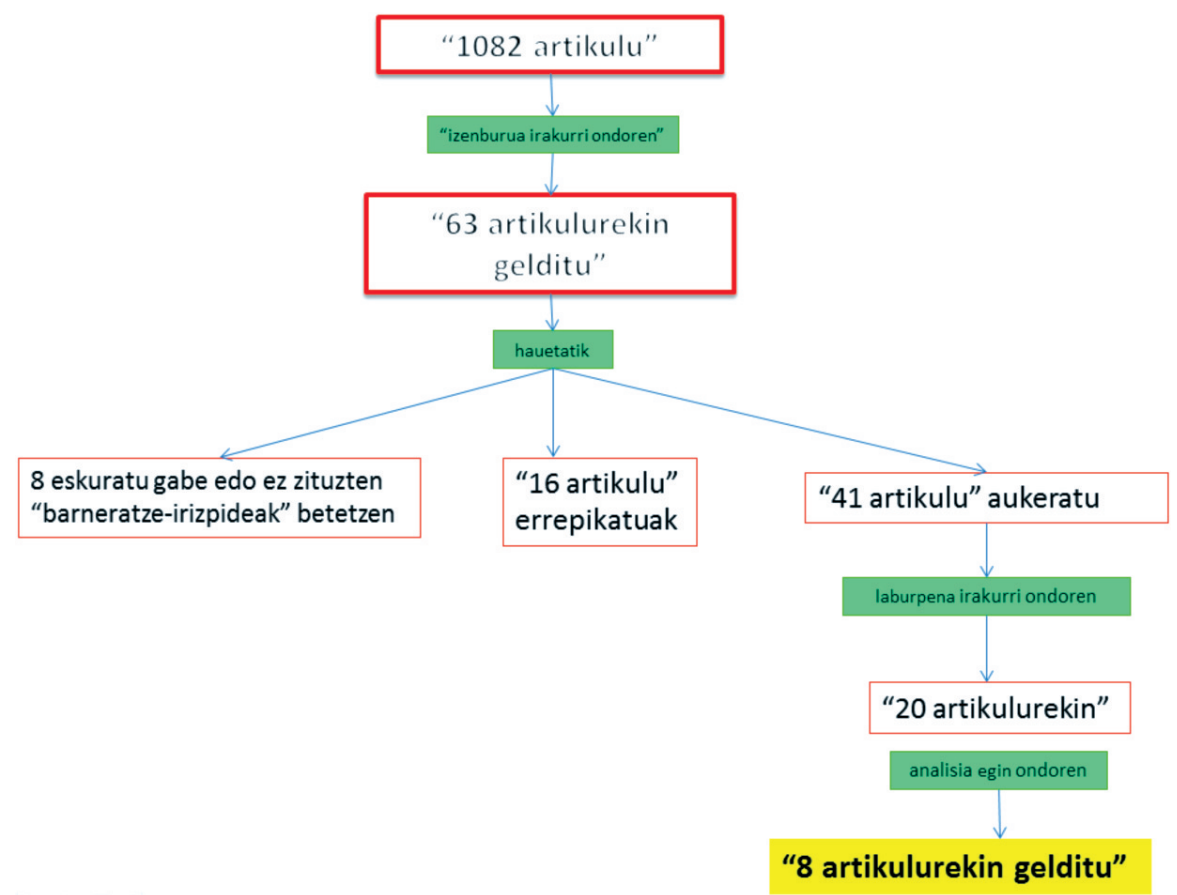

1. irudia. Artikuluen eskuraketaren eskema. 


\section{EMAITZAK}

Emaitzak, lan honen berrikusketa bibliografikoan proposaturiko helburuei jarraituz, aukeratutako zortzi artikulu horietan lortutako informazioan oinarritu dira. Aukeratutako artikuluen ikerketa-diseinuari dagokionez, lau literaturaren berrikusketa sistematikoak dira, hiru kualitatiboak eta bat kuantitatiboa, deskriptiboa eta zeharkakoa. (III. eranskina)

Zortzi artikulu horien berrikusketa egin ondoren, emaitzak zainketa intentsiboetan ingresatuta dagoen pazientearen senideek bizitzen duten esperientziari eta dituzten beharrei zuzenduta daude. Era horretan, bi bloke tematikotan bereizten dira. Lehenengoan, ingresoa gertatu bitartean, familiaren bizipena eta estres-faktoreak zeintzuk diren azaltzen dira. Bigarren bloke tematikoa, ordea, hiru azpimultzotan bereizten da: 1) familiak pazientearen egoera patologikoaren eta ZIUaren ezaugarrien inguruan dituen ezagutzak, hots, behar kognitiboak, 2) familiek euren maitatuaren ingresoan nabaritzen dituzten sentimenduak, hau da, familiaren behar emozionalak, eta bukatzeko, 3) familiak hurbileko gainontzeko jendearekin (gainontzeko familia eta lagunak) dauzkan erlazioak, familiaren behar sozialak. (2. irudia)

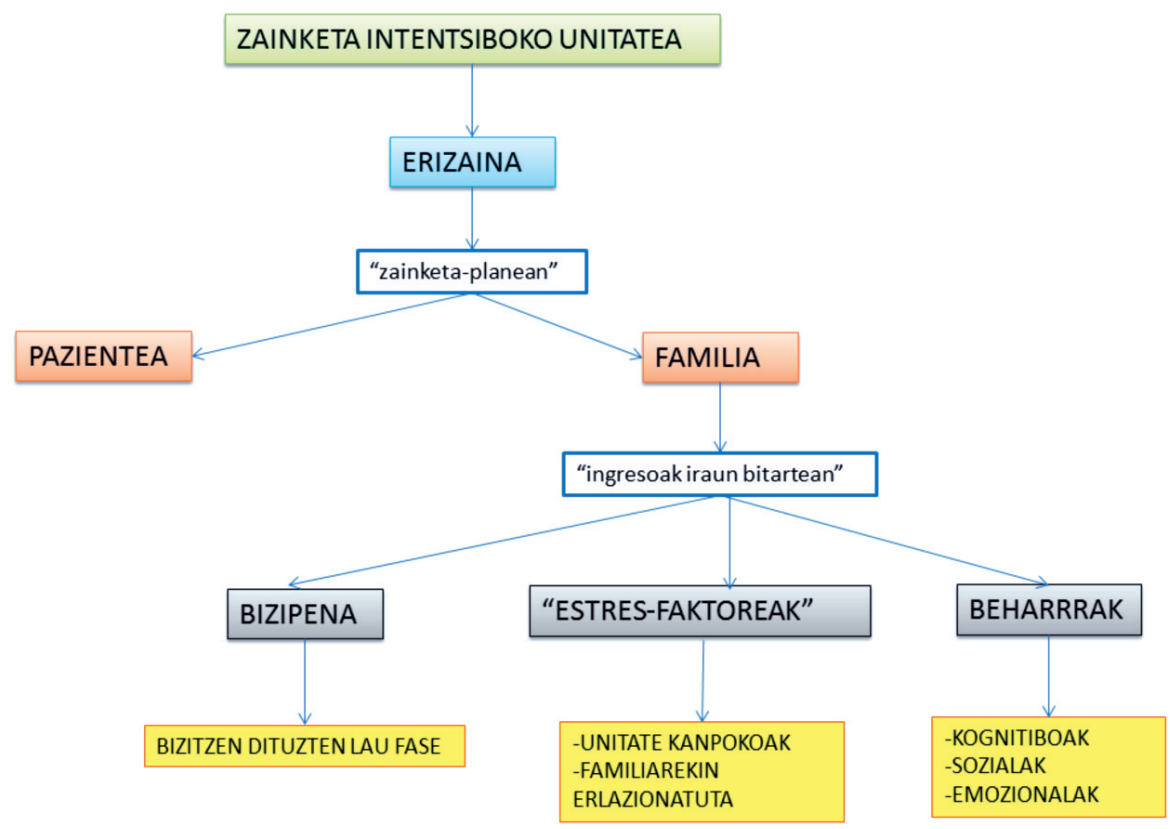

2. irudia. Zuhaitz kategorikoa. 


\subsection{Familiaren bizipena eta estres-faktoreak}

Aipatu bezala, ospitaleratzea norbanakoarentzat zein inguruko familiakidearentzat eta gertuko senideentzat gertaera estresagarria da. Gainera, gertaera larriagotzen da baldin eta ospitaleratzea zainketa intentsiboko unitatean izaten bada [11].

Zainketa intentsiboko erizainek emozio handiko egoera zail ugari bizi dituzte, non familiaren estresa, urduritasuna eta ezjakintasuna ez diren onuragarriak egoerari aurre egiteko. Komenigarria litzateke erizainak familiei ematea egoerari aurre egiteko beharrezkoa duten euskarria. Horretarako, aproposa izango litzateke familiari estres maila handia eragiten dioten faktoreak eta jarrerak ezagutzea, erizainen jokaera familiaren estres maila ahalik eta baxuena izatera bideratzeko. Bide horretan, familia bakoitzari eskaini behar zaion zainketa-planak indibidualizatua izan behar du. Kasu hauetan, estres handien eragiten duten egoerak bi multzotan bereiz daitezke. Alde batetik, unitateak berak sorrarazten dituenak: inguruaren teknifikazioa, intimitate-falta, espazio ezegokiak, egunero pazientea artatzen duen profesional ezezagunen lantaldea handia izatea, konfiantza-falta izatea, hizkera ulertzeko zailtasuna, eta unitatearen arau zorrotzak bete behar izatea. Bestetik, familiarekin zerikusiak dutenak, esaterako, heriotzaren beldurra, egoeraren kontrol-falta izatea, itxaro-uneetan ezjakintasun-sentsazioa eta euren sentimenduak (dudak eta kezkak) azaleratzeko askatasunfalta sentitzea $[12,13]$.

\subsection{Familiaren beharrak}

\subsubsection{Behar kognitiboak}

Hainbat autorek argitaratutako bilaketa bibliografikoan adierazi zuten, irakurritako ikerketa ezberdinetan familiak eskatzen zuen behar garrantzitsuena informazioa jasotzea zela $[14,15]$. Ikerlari horiek ikerketa horretako helburuei erantzuteko proposamen berdinekin lau datu-basetan oinarritu zuten euren bilaketa, Pubmed, Cinhal, Cuiden eta Cochrane Library [14], hain zuzen ere.

Espainia mailako zainketa intentsiboko unitateen $\%$ 77n egunean behin baino ez diote medikuek familiari informazioa ematen. Kasuen \% 70ean medikua bakarrik arduratzen da informazioa emateaz, eta kasuen \% 25ean erizainak eta medikuak, bakoitza bere aldetik, ematen dio informazioa familiari. Azkeneko kasu honek koordinazio-arazoak eta gaizki-ulertzeak areagotzen ditu, baldin eta erizainen eta medikuen arteko interkomunikazioa eskasa bada [16].

Beraz, esan bezala, familiek euren maitatuaren osasun-egoeraren inguruko informazioa jaso nahi dute eta, era berean, pazientearen inguruan zer gertatzen ari den jakin. Ondorioz, ezinbestekoa izango litzateke erizainek 
eta medikuek ematen duten informazioa bateratua eta koordinatua egotea, senideek ahalik eta informazio hoberena jasotzeko.

\subsubsection{Behar emozionalak}

Familiek maitatuaren pronostikoa hobetzearekin eta bizi-itxaropenarekin erlazionaturiko emozioak positibotzat hartuko dituzte; kontrara, gaixoa galtzeko arriskuan egonez gero, negatibotzat joko dituzte [14]. Familien ilusiorik edo itxaropenik inportanteena gaixoa errekuperatzea edo sendatzea da [15].

Emozio-nahaste horiek inpotentzia eta ziurgabetasuna sorrarazten diete, haien maitatua laguntzeko ezgai ikusten direlako. Hori jakinda, zenbait autorek proposatzen dute osasun-profesionalek euskarri emozionala eskaintzea familien ongizatea errazteko. Hala ere, ebidentziak erakutsi du erizainek familien behar emozionalak gutxiesten dituztela eta, horregatik, familiei zainketa gutxi zuzentzen zaizkiela $[14,15]$. Espainia mailan, ZIUen $\%$ 83n ez dute inolako protokolorik erabiltzen familia artatzeko [16].

\subsubsection{Behar sozialak}

Familia-kide bat ZIUan ingresatzeak familiaren rolean, erlazioetan eta gainontzeko familiaren arduran eragina du; ondorioz, errutina apurtzeak familia mailan zein maila sozialean ere eragiten du.

Ikertzaile jakin batzuek ondorioztatu zuten Malagan egindako ikerketa deskriptibo zeharkakoan, Espainiako 98 ZIUetako ordutegien antolaketari buruzko datuak jaso ondoren, 93 ZIUren bisiten kopurua, bisiten iraupena eta bisitarien kopurua mugatuta zegoela: egunean 30 minutuko (\% 59) 2 bisita (\% 64) eta bisita bakoitzean 2 pertsona (\% 65) sar zitezkeen [16].

Ikerlan horretan ateratako datuek ondorioztatzen duten zorroztasunaren kontra, eta aurretik aipatu izan den moduan, gertutasuna, hau da, pazienteengandik gertu egotea, maiztasunez ikustea edota uneoro bere ondoan egotea garrantzitsua da ingurune sozialarentzat. Arrazoi horrengatik, familiek bisiten ordutegiarekiko desadostasuna adierazten dute eta bisitetarako ordutegi malguagoa eskatzen dute $[14,15]$.

\section{EZTABAIDA}

Familiaren behar sozialei dagokienez eztabaida eta ikuspuntu ugari sortu dira; izan ere, zenbait autorek frogatu dute bisiten ordutegia malguagoa izango balitz, familiaren antsietate maila txikiagoa izango litzatekeela eta erosotasun eta poztasun maila handiagoa izango litzatekeela [18]. 
Argudiatze horren aurka, aldiz, Errasti-Ibarrondo B.k eta Tricas-Sauras S.ek aldarrikatzen dute, bisita irekiek erizainen lanaren kontra egingo luketela, eta erizainen estres maila handituko luketela. Bestetik, hainbat autorek unitateen egitura irekia izatea pazientearen intimitatearen kontrako mehatxu modura ikusten dute. Gainera, ordutegi malgua izango balitz, ingurunean zarata altuegia izango litzateke eta pazienteen atsedenean eragina izango luke [17].

Familiak bere senide maitatuaren zainketan parte hartzearekin zerikusia duen beste proposamen bat dago, familiari maitatuaren zainketetan parte-hartzaileago sentitzea ahalbidetuko liokeena $[14,18]$, eta antsietate maila gutxitu $[14,15,18]$. Hainbat autorek 2012. urtean argitaratu zuten bilaketa estrategikoan, ZIUetako bisiten ordutegia handitzeak familiarengan eragin litzakeen efektuak identifikatzeko, deskribatzeko eta laburtzeko helburuarekin, ondorengo emaitzak lortu zituzten, 15 argitalpen aztertu ondoren: familiaren erosotasun maila handitu egiten da pazientearekin denbora gehiago egon ahal izateagatik, eta estres eta antsietate maila gutxitu egiten dira $[18,19]$.

\section{ONDORIOAK}

Bilaketa bibliografiko honetan ZIUetako erizainek pazientearen familiek dituzten beharren identifikazio azkarra egitea aldarrikatzen da. Bilaketa honetan argi ikusi da familiek behar dutela informazio ulergarria, zabala eta beraien kezkak argituko dituena. Horren harira, nork eta zein momentutan ematen duen informazioa aztertu da. Ehuneko handian, ikusi da Espainiako ZIUetan medikuak arduratzen direla informazioa emateaz, erizainen presentziarik gabe. Horrek, erizainek praktika kliniko okerra hartzea eragiten du.

Familiaren ilusioa edo itxaropena pazientearen errekuperazioa dela ondorioztatzen da. Gaixotasunaren pronostikorik ez edukitzeak, hau da, maitatuaren gaixotasunaren prozesua zelan garatuko den ez jakiteak, emozio-nahaste ugari pairatzea eragiten du, eta ziurgabetasuna eta inpotentzia areagotzen ditu. Horren aurrean, baliabide eragingarriena euskarri emozionala ematea komenigarria dela frogatu dute. Hala ere, aztertuta dago osasun-profesionalek emozio horiek gutxiesten dituztela, eta ez dutela horiei buruzko protokolorik.

Ikusitakoarekin, aldaketaren beharra nabarmena da. Gehienetan osasun-profesionalak pazientearen patologian eta egoeran zentratzen dira balorazioa egitean, holistikotasuna galtzen da eta familien zainketaz eta sufrimenduaz ahazten dira. Erizainak era holistikoan jardun behar du.

Aipatu beharra dago familia maitatuarengandik gertu egoteak familiarengan onura eragiten duela, eta sufritzen duten estres eta antsietate maila 
gutxitzen laguntzen duela; baina, unitateen ordutegi mugatuak asko oztopatzen du familiaren eta pazientearen arteko gertutasun hori. Ordutegi malgua edukitzeak familiari onurak baino ez lizkioke ekarriko. Hala ere, zenbait autorek aipatzen dutena azpimarragarria da; izan ere, familia eguneko edozein momentutan sartzeko aukerak erizainaren lan-karga handitzen du.

\section{BIBLIOGRAFIA}

[1] Palanca Sanchez I.Esteban de la Torre A. Elola Somoza J. Informes, estudios e investigaión 2010: Unidad de cuidados intensivos estandares y recomendaciones. Madrid. Ministerio de Sanidad y Política Social. 2010.

[2] Larzelere MM, Jones GN. Stress and health. Prim Care. 2008;35:839-856.

[3] Lazarus, R.S. Theory-based stress-measurement. Psychological Inquiry 1990;(1): 3-13.

[4] Lazarus R.S. y Lazarus B. N. Passion and reason: Making sense of our emotions. New York: Oxford University Press1994.

[5] Pérez M. Experiencias, percepciones y necesidades en la UCI: revisión sistemática de estudios cualitativos. Enfermería global 2008(12):1.

[6] Zaforteza C, Gastaldo D, Sánchez-Cuenca P, de Pedro JE, Lastra P. Relación entre enfermeras de Unidades de Cuidados Intensivos y familiares: Indicios para el cambio. 32004.

[7] Hewitt J. Psycho-affective disorder in intensive care units: a review. J Clin Nurs 2002;11(5):575-584.

[8] Uribe Escalante MT, Muñoz Torres C, Restrepo Ruíz J. Percepción familiar del paciente crítico cardiovascular. Invest.educ.enferm 2004;22(2):50-61.

[9] Llamas-Sánchez F, Flores-Cordón J, Acosta-Mosquera M, González-Vázquez J, Albar-Marín M, Macías-Rodríguez C. Necesidades de los familiares en una Unidad de Cuidados Críticos. Enfermería Intensiva 2009;20(2):50-57.

[10] Campo Martínez M.C., Cotrina Gamboa M.J.. Relación de ayuda al familiar del paciente en situación crítica. Enferm. glob. [revista en la Internet]. 2011 Oct [citado 2013 Dic 09] ; 10(24): . eskugarri: http://scielo.isciii.es/scielo. php?script=sci_arttext\&pid=S1695-61412011000400009\&lng=es. http:// dx.doi.org/10.4321/S1695-61412011000400009

[11] Ahmed SM, Lemkau JP, Hershberger PJ. Psychosocial influences on health. In: Rakel RE, ed. Textbook of Family Medicine. 8th ed. Philadelphia, Pa: Saunders Elsevier; 2011:chap 3.

[12] García Mozo A, Sánchez Roldán F, Amorós Cerdá S, Balaguer Albarracín F, Díez Alcalde M, Durán Torres M, et al. Desarrollo de una guía de atención a los familiares del paciente crítico. Enfermería Intensiva 2010;21(1):20-27.

[13] Pérez M. Experiencias, percepciones y necesidades en la UCI: revisión sistemática de estudios cualitativos. Enfermería global 2008(12):1. 
[14] Pardavila Belio M, Vivar C. Necesidades de la familia en las unidades de cuidados intensivos. Revisión de la literatura. Enfermería intensiva 2012;23(2):51-67.

[15] Verhaeghe S, Defloor T, Van Zuuren F, Duijnstee M, Grypdonck M. The needs and experiences of family members of adult patients in an intensive care unit: a review of the literature. J Clin Nurs 2005 Apr;14(4):501-509.

[16] Velasco Bueno JM, Prieto de Paula, Juan Francisco, Castillo Morales J, Merino Nogales N, Perea-Milla López E. Organización de las visitas de familiares en las unidades de cuidados intensivos en España. Enfermería Intensiva 2005;16(2):73-83.

[17] Zaforteza Lallemand C, Prieto González S, Canet Ferrer T, Díaz López Y, Molina Santiago M, Moreno Mulet C, et al. Mejorando el cuidado a los familiares del paciente crítico: estrategias consensuadas. Enfermería Intensiva 2010;21(1):11-19.

[18] Errasti-Ibarrondo B, Tricas-Sauras S. La visita flexible en las unidades de cuidados intensivos: beneficios para los familiares del paciente crítico. Enfermería intensiva 2012.

[19] Engström B, Uusitalo A, Engström Å. Relatives' involvement in nursing care: A qualitative study describing critical care nurses' experiences. Intensive and Critical Care Nursing 2011;27(1):1-9. 